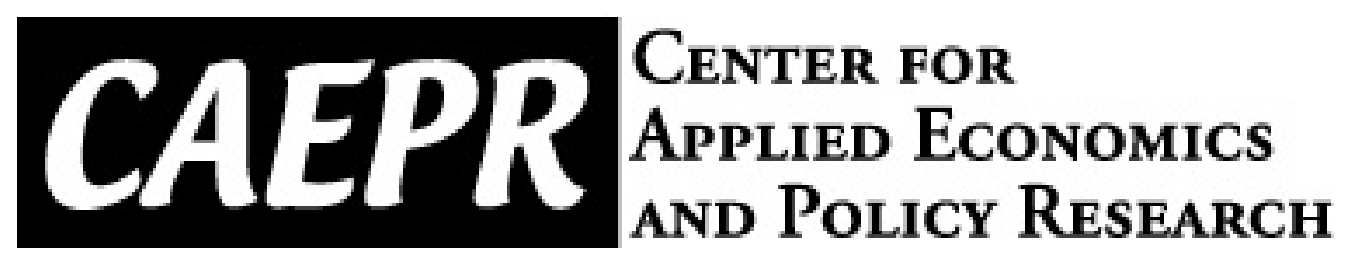

CAEPR Working Paper

\#008-2009

\title{
REPLY TO "GENERALIZING THE TAYLOR PRINCIPLE: A COMMENT"
}

\section{TROY DAVIG AND ERIC M. LEEPER}

Indiana University

May 19, 2009

This paper can be downloaded without charge from the Social Science Research Network electronic library at: http://ssrn.com/abstract=1416904.

The Center for Applied Economics and Policy Research resides in the Department of Economics at Indiana University Bloomington. CAEPR can be found on the Internet at:

http://www.indiana.edu/ caepr. CAEPR can be reached via email at caepr@indiana.edu or via phone at 812-855-4050.

(C2008 by NAME. All rights reserved. Short sections of text, not to exceed two paragraphs, may be quoted without explicit permission provided that full credit, including $₫$ notice, is given to the source. 


\title{
REPLY TO "GENERALIZING THE TAYLOR PRINCIPLE: A COMMENT"
}

\author{
TROY DAVIG AND ERIC M. LEEPER*
}

\begin{abstract}
Farmer, Waggoner, and Zha (2009) show that a new Keynesian model with a regime-switching monetary policy rule can support multiple solutions that depend only on the fundamental shocks in the model. Their note appears to find solutions in regions of the parameter space where there should be no bounded solutions, according to conditions in Davig and Leeper (2007). This puzzling finding is straightforward to explain: Farmer, Waggoner, and Zha (FWZ) derive solutions using a model that differs from the one to which the Davig and Leeper (DL) conditions apply. FWZ's multiple solutions rely on special assumptions about the correlation structure between fundamental shocks and policy regimes, blurring the distinction between "deep" parameters that govern behavior and the parameters that govern the exogenous shock processes, and making it difficult to ascribe any economic interpretation to FWZ's solutions.
\end{abstract}

Forward-looking economic agents base decisions not only on monetary policy choices today, but also on the expected future path of policy choices. Troy Davig and Eric M. Leeper (2007) examine the implications of this basic feature of rational expectations in environments in which policy rules, or regimes, undergo recurring changes. When agents' expectations functions embed the possibility of policy regime changes in the future, the nature of rational expectations equilibria can be altered in fundamental ways.

Spillovers from anticipated future regimes can dramatically change the current equilibrium. Even if current policy hawkishly reacts to combat incipient inflation, for example, the possibility of moving to a more dovish regime in the future can 
raise the volatility of inflation today. Because determinacy of equilibrium depends on policy behavior in the long run, conditions for a determinate equilibrium depend on current policy, all possible future policies, and the transition probabilities among policy regimes. Characteristics of the entire policy process - something akin to Davig and Leeper's "long-run Taylor principle" — determine whether a model has a unique equilibrium. This is the idea behind generalizing the Taylor principle.

Roger E. A. Farmer, Daniel Waggoner, and Tao Zha (2009a) show that a new Keynesian model with a regime-switching monetary policy rule can support multiple solutions that depend only on the fundamental shocks in the model. Their note appears to find solutions in regions of the parameter space where there should be no bounded solutions, according to conditions in Davig and Leeper (2007). This puzzling finding is straightforward to explain: Farmer, Waggoner, and Zha (FWZ) and Davig and Leeper (DL) study determinacy of equilibrium in different models. Perhaps more importantly, the FWZ solutions also rest on cross-equation restrictions between behavioral relations and the exogenous driving process. As a consequence of this rather special assumption, the processes governing the exogenous variables must be a particular function of all the parameters of the model-private and policyundermining the sharp distinctions among "deep parameters" that are typical in optimizing models. ${ }^{1}$ With these conventional distinctions abandoned, it is difficult to ascribe economic interpretations to FWZ's additional solutions. We, therefore, disagree with FWZ's conclusion that there is "no economic reason to prefer one subset of fundamental equilibria over another."

FWZ derive their results using a quasi-linear version of an underlying non-linear model. DL derive determinacy conditions using a linear representation of the quasilinear setup. The linear representation captures many of the interesting non-linearities induced by regime switching. DL prove that the minimum state variable (MSV) solution to the linear representation is the unique bounded solution, so long as policy 
behavior satisfies the long-run Taylor principle. Although that MSV solution also solves the quasi-linear system, DL make no claims about determinacy of the solution for the quasi-linear model: non-linearity induced by the regime-switching policy process may permit non-MSV solutions to exist. FWZ derive a class of such non-MSV solutions. Because these solutions apply to the quasi-linear model, FWZ's claim of finding a "counterexample" to DL's determinacy proposition is inaccurate. DL provide necessary and sufficient conditions for determinacy of a bounded equilibrium of the linear representation, while FWZ do not provide such conditions for the quasilinear system.

To some readers, FWZ's comment may raise a more fundamental question: does a generalized Taylor principle exist? Can a monetary authority uniquely determine the equilibrium even though policy occasionally has periods when it behaves passively? This question is of more than just theoretical interest. Even inflation targeting central banks have multiple objectives. They care about financial stability, output fluctuations, labor market developments, and low and stable inflation rates. Recent central bank actions around the world demonstrate myriad ways in which monetary policy can deviate from the Taylor principle to address these other concerns. Do such excursions into passive policy behavior risk leaving inflation expectations unanchored and threaten to destabilize the inflation process? If a generalized, or long-run, Taylor principle exists and monetary policy obeys that generalized principle, then indeterminacy of equilibrium is not necessarily created by periods of passive policy behavior. Nothing in FWZ's comment diminishes the efficacy or the usefulness of the notion of a generalized Taylor principle. Naturally, the precise nature of the long-run Taylor principle depends on the model under consideration and the definition of determinacy employed. In any case, the generalized Taylor principle is alive and well. 


\section{Quasi-Linear vs. Linear Representations}

DL lay out a framework that allows researchers to employ existing tools to solve and analyze purely forward-looking Markov-switching rational expectations models. The new Keynesian model with linearized private sector relations and a switching monetary policy rule is the laboratory for our approach. We specify that setup as

$$
\left.\begin{array}{c}
x_{t}=E_{t} x_{t+1}-\sigma^{-1}\left(i_{t}-E_{t} \pi_{t+1}\right)+u_{t}^{D}, \\
\pi_{t}=\beta E_{t} \pi_{t+1}+\kappa x_{t}+u_{t}^{S}, \\
i_{t}=\alpha\left(s_{t}\right) \pi_{t}+\gamma\left(s_{t}\right) x_{t} .
\end{array}\right\}
$$

We will refer to this representation as model "QL," for quasi-linear. It has an appropriate log-linearization of the underlying non-linear model describing private sector behavior, the first two equations, but the monetary policy rule, the third equation, is non-linear. Equilibria in these models include expectations formation effects that capture how behavior in one regime spills over to affect equilibrium outcomes in other regimes.

It is straightforward to solve the QL model using the method of undetermined coefficients. That solution method, however, is silent on whether the solution is unique. To derive conditions for determinacy of equilibrium, DL rewrite expectations by distributing probability mass for the two possible regimes, $s_{t}=1,2$, across the conditional expectations for inflation and output as follows

$$
\begin{aligned}
& E_{t} \pi_{t+1}=E\left[\pi_{t+1} \mid s_{t}=i, \Omega_{t}^{-s}\right]=p_{i 1} E\left[\pi_{1 t+1} \mid \Omega_{t}^{-s}\right]+p_{i 2} E\left[\pi_{2 t+1} \mid \Omega_{t}^{-s}\right], \\
& E_{t} x_{t+1}=E\left[x_{t+1} \mid s_{t}=i, \Omega_{t}^{-s}\right]=p_{i 1} E\left[x_{1 t+1} \mid \Omega_{t}^{-s}\right]+p_{i 2} E\left[x_{2 t+1} \mid \Omega_{t}^{-s}\right],
\end{aligned}
$$

where $\pi_{i t}=\pi_{t}\left(s_{t}=i, u_{t}^{D}, u_{t}^{S}\right), x_{i t}=x_{t}\left(s_{t}=i, u_{t}^{D}, u_{t}^{S}\right)$, for $i=1,2$. The information set, $\Omega_{t}^{-s}=\left\{s_{t-1}, \ldots, r_{t}, r_{t-1}, \ldots\right\}$, excludes the current regime, so $\Omega_{t}=\Omega_{t}^{-s} \cup\left\{s_{t}\right\}$. An important maintained assumption in DL is that the fundamental shocks, $\left(u_{t}^{D}, u_{t}^{S}\right)$, are independent of the regime, $s_{t}$. This approach to specifying conditional expectations 
for inflation is similar to the approaches in Stephen Gordon and Pascal St-Amour (2000) and Ravi Bansal and Hao Zhou (2002). These expressions for expectations strike us as completely natural, particularly since we cannot take a first-order approximation to the policy rule because the reaction coefficients are not differentiable in the state variable.

The benefit of writing expectations as in (1)-(2) is that after substituting the expressions for expectations into $(\mathrm{QL})$, one obtains the following linear representation

$$
A Y_{t}=B Y_{t-1}+A \eta_{t}+C u_{t}
$$

where $Y_{t}$ contains regime-dependent values for inflation and output, $\eta_{t}$ are the regimedependent one-step-ahead forecast errors, and $u_{t}$ are the fundamental shocks (see our original paper for additional details). We refer to this representation as model "L" for linear, since it is a linear system of expectational difference equations. The coefficient matrices embed the transition probabilities governing regime change and regime-dependent parameters. Further, we show that the unique bounded solution to model L corresponds exactly to the solution using the method of undetermined coefficients on the minimum set of state variables - the MSV solution. Model L is extremely tractable. It allows one to compute the solution, check for determinacy, and even estimate regime-switching rational expectations models using traditional tools designed for fixed-regime models [see, for example, Davig and Taeyoung Doh (2008)].

Using model L, we show that a passive monetary policy regime need not induce indeterminacy if agents expect a future shift to a more active policy - the idea of a generalized Taylor principle. However, the passive regime cannot be "too passive" or be expected to last "too long," notions made precise by the long-run Taylor principle that DL derive. Too much passive policy behavior violates the long-run Taylor principle and produces multiple equilibria that are subject to sunspot fluctuations. 
Importantly, our results regarding determinacy apply to model L, something the technical results in the paper make clear. FWZ acknowledge we do not make claims regarding determinacy for model QL and state, “... Davig and Leeper's generalized Taylor principle implies a unique bounded equilibrium of the expanded linear system," the model in (L) [FWZ Section V]. FWZ's multiple (non-MSV) solutions, therefore, do not constitute a counterexample to our results.

FWZ's statements are misleading in another dimension also. They refer to model QL as the original non-linear model. But the first two equations of (QL) come from log-linearizing private sector relations around the deterministic steady state. Nonlinearity arises entirely by allowing the coefficients in the policy rule to switch. Clearly, model QL is not the original non-linear model. ${ }^{2}$ FWZ provide no argument for why model QL is intrinsically more interesting than model L. As the examples in DL illustrate and our comments below amplify, it is clear that model L captures essential non-linearities that arise from regime switching. Those non-linearities, together with model L's tractability, make it an appealing object with which to work.

\section{Discussion of the FWZ Fundamental Equilibria}

FWZ's non-MSV solution is a linear combination of the MSV solution and an autoregressive term. It takes the form

$$
\begin{aligned}
& y_{t}=G_{s_{t}} u_{t}+V \omega_{t}, \\
& \omega_{t}=\Lambda_{s_{t}} \omega_{t-1}+M_{s_{t} s_{t-1}} u_{t}
\end{aligned}
$$

where $y_{t}=\left[\pi_{t}, x_{t}\right]^{\prime}, u_{t}$ are fundamental shocks and $\omega_{t}$ is an autoregressive component that affects the equilibrium at time $t$. The solution in (3) consists of two parts: the MSV solution, $G_{s_{t}} u_{t}$, and the non-MSV part, $\omega_{t}$. Because $\omega_{t}$ is a distributed lag of $u_{t}, u_{t-1}, u_{t-2}, \ldots$, the autoregressive term embodies the minimum state, $u_{t}$, that suffices to construct a solution to model QL plus the entire history of the fundamental 
shocks, $u_{t-s}, s>0$. The volatility of the non-MSV component is not uniquely determined, since $M_{s_{t}, s_{t-1}}$ can be any $1 \times 2$ real matrix. $\Lambda_{s_{t}}$ is zero when $s_{t}$ corresponds to the active monetary regime and $\left|\Lambda_{s_{t}}\right|<1$ when $s_{t}$ corresponds to the passive regime. Below, we refer to (3)-(4) as the FWZ solution.

To keep the solution bounded, FWZ require that the autoregressive parameters of the non-MSV term, $\Lambda_{s_{t}}$, change precisely when regime changes. The serial correlation properties of the non-MSV component must switch in a manner that is perfectly synchronized with changes in the monetary policy regime. In an example in section $\mathrm{V}$ of FWZ's comment, the matrix $V$ in (3) is determined by the eigenvector of the system in the passive regime, while $\Lambda_{s_{t}}$ is determined by the associated eigenvalue and the probability of policy remaining passive if it is already passive. Evidently, the persistence and volatility of the non-MSV part of the solution depend, not on a hypothesized exogenous process, but on an "exogenous" process whose properties depends on all the parameters in the model.

To be sure, FWZ's non-MSV solution is technically valid. But the solution is valid only because the cross-equation restrictions between behavioral parameters and the process governing the shocks in the non-MSV component ensure that the solution remains bounded. An implication of these restrictions is that some parameters play a dual role - as both "deep parameters" and as parameters governing the serial correlation of non-MSV component of the solution. For example, the frequency of price adjustment - the so-called "Calvo parameter" — and the serial correlation of the nonMSV component, determined by $\Lambda_{s_{t}}$, cannot be chosen independently. This unusual state of affairs renders problematic any economic interpretation of the non-MSV solution. We certainly do not object to cross-equation restrictions between relations describing private sector behavior. But these are not your father's cross-equation 
restrictions - the ones that Sargent (1981) labels the "hallmark of rational expectations." We do object to cross-equation restrictions between the parameters describing preferences and technology and those that characterize the exogenous driving processes.

One possible way of interpreting the non-MSV solution, albeit somewhat artificially, is that shifts in monetary policy may also trigger shifts in the serial correlation structure of the shocks. We certainly advocate modeling policy regime change as triggered by economic developments. This is the approach that Davig and Leeper (2006a) take when they model periods when the central bank may move to a strongly active regime as a consequence of high and rising inflation. However, there is no reason to imagine that plausible methods for endogenizing regime change are consistent with the cross-equation restrictions that the non-MSV solutions require. In fact, Davig (2007) studies optimal monetary policy responses to Markov switching in the structure of the private economy and finds that policy rules may or may not display switching, depending on exactly how the optimal policy problem is posed. Although it is possible for optimal policy switching to be correlated with switches in private behavior, optimal policy choices surely will not support the introduction of the additional free parameters in the elements of $M_{s_{t}, s_{t-1}}$ in (4).

What does the non-MSV solution in (3) and (4) deliver? The infinite-order moving average of the fundamental shocks, coupled with the freedom to arbitrarily change the volatility of the fundamental shocks through the free parameters in $M_{s_{t}, s_{t-1}}$, will enhance any model's ability to fit the persistence and variability of observed data. Thomas A. Lubik and Frank Schorfheide (2004), for example, find that indeterminacy of equilibrium allows a new Keynesian model to match U.S. data in the 1960s and 1970s, when both volatility and inflation persistence were quite high. While we are all for improved fit to data, in the case of non-MSV solutions, the improvement does 
not spring from economic modeling; it comes entirely from arbitrary modifications to exogenous shock processes.

Another issue bears on whether FWZ's non-MSV solution captures important regime-switching-induced non-linearities that an MSV solution satisfying the longrun Taylor principle in the linear system cannot capture. It turns out that the MSV solution does capture some key non-linearities. Regions of the parameter space that delineate where determinate equilibria arise tend to be hyperbolic in DL, where they would be linear in fixed-regime versions of the models [figures 1-3 in DL]. DL displays hump-shaped responses of inflation and output to demand shocks, whereas these responses are monotonic when regime is fixed [figure 5 in DL]. Hump-shaped responses to demand shocks are a desideratum of macro modeling. FWZ make no claim that the non-MSV solution captures important non-linearities that the MSV solution misses.

It is also clear that the MSV solution attains outcomes that are impossible in linear models without regime change. Consider DL's simple Fisherian economy, with the monetary policy rule $i_{t}=\alpha\left(s_{t}\right) \pi_{t}$, where $s_{t}$ is the regime at $t, \alpha\left(s_{t}=1\right)=\alpha_{1}$, and $\alpha\left(s_{t}=2\right)=\alpha_{2}$. Posit that $\alpha_{1}, \alpha_{2}$, and the transition probabilities governing the policy regime switching satisfy the long-run Taylor principle, so that the bounded equilibrium is unique. The solution for inflation when the real interest rate, $r_{t}$, is an i.i.d random variable, is given by

$$
\pi_{i t}=\frac{1}{\alpha_{i}} r_{t}, \quad i=1,2
$$

where $\alpha_{1}>1$ is the active policy regime and $0<\alpha_{2}<1$ is the passive regime. DL show that $\alpha_{2}$ can be arbitrarily close to 0 and the variance of inflation in regime 2 and unconditionally — can be arbitrarily large, yet policy satisfies the long-run Taylor principle and the equilibrium is determinate. Determinacy requires that the passive regime be sufficiently short-lived and visited sufficiently infrequently. A solution like (5), in which monetary policy behavior amplifies the impacts of the shock to real 
interest rates, is impossible in a conventional fixed-regime model with a determinate equilibrium.

Finally, there are ways of selecting among the different fundamental equilibria. William A. Branch, Davig, and Bruce McGough (2008) endow agents with adaptive expectations and use learnability as an equilibrium selection criterion. They show that the long-run Taylor principle, which delivers a determinate bounded equilibrium in the linear system, ensures learnability of the MSV solution when agents formulate expectations by recursively estimating a VAR. Learnability of non-MSV solutions, however, is more complicated and cannot arise unless agents are endowed with particular knowledge regarding the lag structure of the model.

\section{Recent Progress and Directions Forward}

Both DL's paper and FWZ's comment focus on bounded equilibria. DL derive necessary and sufficient conditions for the existence of a unique bounded equilibrium of the expanded linear system, L. FWZ show that these conditions are necessary but not sufficient for a bounded solution to the quasi-linear system, QL. Necessary and sufficient conditions for a bounded solution to (QL) have not yet been derived.

Although DL argue that the boundedness definition of determinacy makes regimeswitching equilibria analogous to fixed-regime equilibria, other definitions of determinacy are also possible and perfectly reasonable. Following the engineering literature, for example, Lars E. O. Svensson and Noah Williams (2007, 2008) solve for equilibria that are bounded in expectation, or mean-square stable. Chung, Davig, and Leeper (2007) also employ boundedness in expectation in their proof of determinacy of equilibrium in a simple model with monetary and fiscal policy switching. Jess Benhabib (2009) derives general conditions for Markov-switching rational expectations models that imply a unique solution within various classes of solutions, such as the class of 
mean-square stable solutions. Farmer, Zha, and Waggoner (2009b) derive analogous conditions for the particular case of the new Keynesian model with a regime switching monetary policy rule. This research derives conditions that allow a complete partition of the parameter space into determinate and indeterminate regions, given that the class of solutions is mean-square stable.

Under this less stringent definition of stability, the original notion of a generalized Taylor principle survives for the quasi-linear model. This generalization implies that an active monetary policy regime can eliminate indeterminacy in a passive monetary regime, but the conditions depend on coefficients in each monetary policy rule and the expected duration of each regime, just as in DL's long-run Taylor principle. Farmer, Zha, and Waggoner (2009b) echo this when they explain that when the generalized Taylor principle holds, "it is the set of regimes that is determinate" (italics in the original). Their work and Benhabib's (2009) allows a complete partitioning of the parameter space that permits researchers to advance the applications of Markovswitching dynamic stochastic general equilibrium models. These advances suggest that in both theoretical and empirical realms, Markov-switching rational expectations models face a bright future. 


\section{Endnotes}

*May 19, 2009. Research Department, Federal Reserve Bank of Kansas City, Troy.Davig@kc.frb.org; Department of Economics, Indiana University and NBER, eleeper@indiana.edu. We thank Todd Walker for helpful conversations and Jess Benhabib for useful communications on this topic.

${ }^{1}$ The "exogenous" driving process in FWZ's solution is a moving average of past fundamental shocks. The serial correlation properties of this term are subject to cross-equation restrictions and, therefore, depend on the "deep parameters" describing preferences and technology.

${ }^{2}$ Davig and Leeper (2006b) provide details regarding the solution to the full non-linear New Keynesian model with regime-switching monetary and fiscal policy. Other papers that solve full non-linear dynamic stochastic general equilibrium models with regime-switching policies include David Andolfatto and Paul Gomme (2003), Davig (2003), Hess Chung, Davig, and Leeper (2007). 


\section{References}

Andolfatto, David, and Paul Gomme. 2003. "Monetary Policy Regimes and Beliefs." International Economic Review, 44(1): 1-30.

Bansal, Ravi, and Hao Zhou. 2002. "Term Structure of Interest Rates with Regime Shifts." Journal of Finance, 57(5): 1997-2043.

Benhabib, Jess. 2009. "A Note on Regime Switching, Monetary Policy and Multiple Equilibria." New York University Manuscript.

Branch, William A., Troy Davig, and Bruce McGough. 2008. "Adaptive Learning in Regime-Switching Models." Federal Reserve Bank of Kansas City RWP 07-09.

Chung, Hess, Troy Davig, and Eric M. Leeper. 2007. "Monetary and Fiscal Policy Switching." Journal of Money, Credit and Banking, 39(4): 809-842.

Davig, Troy. 2004. "Regime-Switching Debt and Taxation." Journal of Monetary Economics, 51(4): 837-859.

Davig, Troy. 2008. "Phillips Curve Instability and Optimal Monetary Policy." Federal Reserve Bank of Kansas City RWP 07-04.

Davig, Troy, and Taeyoung Doh. 2008. "Monetary Policy Shifts and Inflation Persistence." Federal Reserve Bank of Kansas City RWP 08-16.

Davig, Troy, and Eric M. Leeper. 2006a. "Endogenous Monetary Policy Regime Change." In NBER International Seminar on Macroeconomics 2006, eds. Lucrezia Reichlin and Kenneth D. West, 345-377. Cambridge, MA: MIT Press.

Davig, Troy, and Eric M. Leeper. 2006b. "Fluctuating Macro Policies and the Fiscal Theory." In NBER Macroeconomics Annual 2006, eds. Daron Acemoglu, Kenneth Rogoff, and Michael Woodford, 247-298. Cambridge, MA: MIT Press. 
Davig, Troy, and Eric M. Leeper. 2007. "Generalizing the Taylor Principle." American Economic Review, 97(3): 607-635.

Farmer, Roger E. A., Daniel Waggoner, and Tao Zha. 2009a. "Generalizing the Taylor Principle: A Comment." Forthcoming in American Economic Review.

Farmer, Roger E. A., Tao Zha, and Daniel Waggoner. 2009b. "Understanding Markov-Switching Rational Expectations Models." NBER Working Paper No. 14710 .

Gordon, Stephen, and Pascal St-Amour. 2000. "A Preference Regime Model of Bear and Bull Markets." American Economic Review, 90(4): 1019-1033.

Lubik, Thomas A., and Frank Schorfheide. 2004. "Testing for Indeterminacy: An Application to U.S. Monetary Policy. American Economic Review, 94(1): 190-217.

Sargent, Thomas J.. 1981. "Interpreting Economic Time Series." Journal of Political Economy, 89(2): 213-248.

Svensson, Lars E. O., and Noah Williams. 2007. "Monetary Policy with Model Uncertainty: Distribution Forecast Targeting." University of Wisconsin Manuscript.

Svensson, Lars E. O. and Noah Williams. 2008. "Optimal Monetary Policy Under Uncertainty: A Markov Jump-Linear-Quadratic Approach.” Federal Reserve Bank of St. Louis Review, 90(4), 275-293. 